\title{
Inhaltsübersicht
}

Allgemeine Einleitung

Rdn

A. Die GmbH im deutschen Recht

I. Grundlagen des GmbH-Rechts . . . . . . . . . . 1

II. Rechtsquellen . . . . . . . . . . . . . . 54

III. Rechtstatsachen ... . . . . . . . . . . . 67

IV. Entwicklungen des GmbH-Rechts . . . . . . . . . . . . 92

B. Die GmbH im internationalen Recht

I. Internationales Gesellschaftsrecht . . . . . . . . . . . . 106

II. Fremdenrecht . . . . . . . . . . . . . . . . 189

III. Rechtsangleichung in der EG . . . . . . . . . . 200

Behrens

Erster Abschnitt

Errichtung der Gesellschaft

51 Zweck

\ 2 Form des Gesellschaftsvertrages

\$ 3 Inhait des Gesellschaftsvertrages

S 4 Firma

f 5 Stammkapital, Stammeinlage

$\$ 6$ Geschäftsführer

$\$ 7$ Anmeldung

S 8 Inhalt der Anmeldung

$\int 9$ Geldeinlage statt Sacheinlage

$\$ 9$ a Ersatzansprüche der Gesellschaft

$\$ 9 \mathrm{~b}$ Verzicht auf Ersatzansprüche

$\int 9 \mathrm{c}$ Ablehnung der Eintragung

$\$ 10$ Eintragung in das Handelsregister

$\$ 11$ Rechtszustand vor der Eintragung

$\$ 12$ Zweigniederlassung

\section{Zweiter Abschnitt}

Rechtsverhältnisse der Gesellschaft und der Gesellschafter

$\$ 13$ Juristische Person; Handelsgesellschaft Raiser Anhang: Durchgriff Mertens

$\$ 14$ Geschäftsanteil

$\$ 15$ Ubetragung von Geschäftsanteilen

Raiser

Anhang: Der Geschäftsanteil im Rechtsverkehr

Zutt

$\$ 16$ Rechtsstellung von Veräußerer und Erwerber

$\$ 17$ Veräußerung von Teilen eines Geschäftsanteils

$\$ 18$ Mitberechtigung am Geschäftsanteil

$\$ 19$ Einzahlungen auf die Stammeinlage

$\$ 20$ Verzugszinsen

Ulmer

Müller 
S21 Kaduzierung

S 22 Haftung der Rechtsvorgänger

\ 23 Versteigerung des Geschäftsanteils

S 24 Aufbringung von Fehlbeträgen

S 25 Zwingende Vorschriften

S 26 Nachschußpflicht

S 27 Unbeschränkte Nachschußpflicht

S 28 Beschränkte NachschuBpflicht

S 29 Verteilung des Reingewinns

Anhang: Genußrechte

Goerdeler/Müller

S 30 Rückzahlungen

Anhang: Gesellschafterhaftung bei Unterkapitalisierung

S 31 Erstattung von verbotenen Rückzahlungen

S 32 Rückzahlung von Gewinn

S 32 a Rückgewähr von Darlehen

S 32 b Haftung

S 33 Erwerb eigener Geschäftsanteile

S 34 Einziehung (Amortisation)

Anhang: Ausschließung und Austritt von Gesellschaftern

Ulmer

Goerdeler/Müller

Ulmer

Hohner

Ulmer 